\title{
Primary Aldosteronism With Type 2 Diabetes Mellitus Requires More Antihypertensive Drugs for Blood Pressure Control: A Retrospective Observational Study
}

\author{
Kennosuke Ohashi ${ }^{a}$, Takeshi Hayashia, Yui Watanabea ${ }^{a}$ Koichiro Hara ${ }^{a}$, Rikako Ukichia, \\ Hiroshi Asano ${ }^{a}$, Hirofumi Suzukia ${ }^{a}$ Kenji Yamashiro ${ }^{a}$, Katsuyoshi Tojo ${ }^{\text {a }}$ \\ Masaya Sakamoto ${ }^{\text {a, }}$, Kazunori Utsunomiya ${ }^{\mathrm{a}}$
}

\begin{abstract}
Background: Diabetes mellitus (DM) and primary aldosteronism (PA) have been reported to induce drug-resistant hypertension and atherosclerosis. It is likely that blood pressure (BP) control becomes far more difficult in PA patients with DM. However, precise clinical characteristics of PA with type 2 DM especially in the aspect of BP control are not clear.
\end{abstract}

Methods: The study included 18 patients who were diagnosed as PA with DM and 52 PA patients without DM who matched age and sex and chosen as a control group. We have compared differences in BP control, use of antihypertensive agents and clinical characteristics between PA patients with and without DM.

Results: There was no difference with regard to the duration of hypertension and BP control between either group. Interestingly, the PA with DM group was found to require more antihypertensive agents than the PA without DM group (number of antihypertensive agents used, $2.0 \pm 1.5$ vs. $1.3 \pm 1.1 ; \mathrm{P}<0.05$, respectively). In the 28 patients who underwent measurement of central BP (CBP) values, plasma aldosterone concentration (PAC) was high in the PA with DM group. Furthermore, a positive correlation was shown between PAC and $\mathrm{CBP}(\mathrm{r}=0.58 ; \mathrm{P}<0.01)$; the higher the PAC, the higher the CBP of patient.

Conclusions: These results might suggest that hypertension becomes more difficult to control in PA patients with DM in the future.

Keywords: Primary aldosteronism; Type 2 diabetes mellitus; Blood pressure control; Antihypertensive agents; Central blood pressure

Manuscript submitted October 18, 2017, accepted October 31, 2017

aDivision of Diabetes, Metabolism and Endocrinology, Department of Internal Medicine, the Jikei University School of Medicine, 3-25-8 Nishishinbashi, Minato-ku, Tokyo 105-8461, Japan

${ }^{\mathrm{b}}$ Corresponding Author: Masaya Sakamoto, Division of Diabetes, Metabolism and Endocrinology, Department of Internal Medicine, the Jikei University School of Medicine, 3-25-8 Nishishinbashi, Minato-ku, Tokyo 105-8461, Japan. Email: m-sakamoto@umin.ac.jp

doi: https://doi.org/10.14740/jocmr3233w

\section{Introduction}

The global prevalence of diabetes is increasing [1], with also the incidence of associated cardiovascular (CV) death. Almost half of type 2 diabetic patients are reported to have hypertension during their lifetime [2-4]. The coexistence of hypertension and diabetes mellitus (DM) especially increases the risk of $\mathrm{CV}$ events, and hypertension represents the most important of all the prognostic factors for DM patients [5]. Upregulation of the renin-angiotensin-aldosterone system (RAAS) has been associated to the physiopathology of hypertension in DM patients [6]; therefore, angiotensin-converting enzyme (ACE) inhibitors and angiotensin receptor blockers (ARBs) represent the first choice antihypertensive drugs for these patients. While blood pressure (BP) control is reported to reduce CV events and associated mortality [7-9], antihypertensive monotherapy often proves inadequate with two-thirds of the patients with hypertension and requires two or more antihypertensive agents for BP control in clinical settings [10-12].

On the other hand, primary aldosteronism (PA) results from the oversecretion of aldosterone from the adrenal glands and represents one of the common causes of secondary hypertension. In recent years, PA has become increasingly diagnosed or detected due to clinical practice guidelines for PA becoming available $[13,14]$ and advances in imaging technology, and it is reported to account for $5-10 \%$ of all hypertension cases [1518]. Delays in the diagnosis of PA are thought to lead to the onset of treatment-refractory hypertension, thus causing damage to such organs as the brain, CV system and kidneys [19-21]. It is crucial to take measures to ensure that PA is diagnosed and treated early since it can be cured with appropriate diagnostic and therapeutic measures.

It has been reported that $15-17 \%$ of PA patients have complications due to diabetes which are higher than the approximately $9 \%$ prevalence in the general population $[22,23]$. However, to date, the clinical characteristics of PA patients with $\mathrm{DM}$ and their response to antihypertensive therapy remain less well characterized. Therefore, in this study, we have compared differences in BP control, use of antihypertensive agents and clinical characteristics between PA patients with and without DM. 


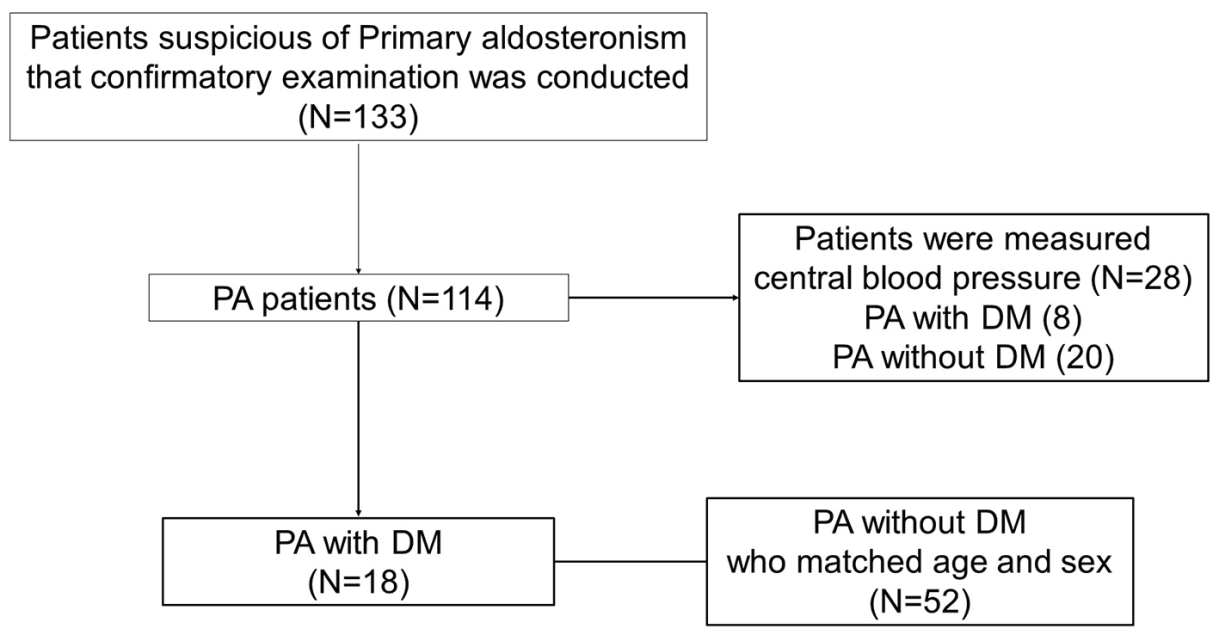

Figure 1. The study included a total of 70 patients. The 18 patients were diagnosed as PA with DM. As control group, 52 PA patients without DM who matched age and sex were chosen in this study. The central blood pressure was measured in 28 PA patients, including eight PA with DM and 20 PA without DM.

\section{Materials and Methods}

\section{Patients and data collection}

This study was submitted to the institutional review board at the Jikei University School of Medicine for review and approval as a retrospective observational study and approved (approval number 26-338).

The 114 patients diagnosed with PA were treated in an inpatient setting at our hospital between April 2008 and December 2014 and type 2 DM was defined according to the guidelines of the Japan Diabetes Society [24]. Patients were excluded if their BP or HbA1c were deficient and 18 patients were diagnosed as PA with DM. The study included a total of 70 patients. The 52 PA patients without DM who matched age and sex were chosen as a control group for this study (Fig. 1).

Diagnosis of PA was conducted according to the Japan Endocrine Society guideline [16]. All patients being treated with ACE inhibitors, ARBs, mineralocorticoid receptor (MR) antagonists and $\beta$-blockers at initial presentation were switched to calcium channel blockers (CCBs) and $\alpha$-blockers. Their medical records were examined for endocrine status, BP control, and use of therapeutic agents. BP was measured in the right arm in all patients while in a sitting position using sphygmomanometer (ADVANCE BP-203RVIIIC/D Omron Colin Inc., Tokyo, Japan) (Korotkoff I and V) and central BP (CBP) was measured using HEM 9000 AI (Omron Colin Inc., Tokyo, Japan). The BP was measured in the morning in the outpatient department before switching to CCBs and $\alpha$-blockers.

\section{Statistical analysis}

Continuous variables are presented as mean \pm standard devia- tion and compared by analysis of variance, paired $t$-test, or Mann-Whitney U test, as appropriate. Pearson's correlation coefficients were used to examine correlations between two variables. A P value of $<0.05$ was considered significant in all analyses. All statistical analyses were performed using SPSS Statistics 22 (IBM Japan Inc., Tokyo, Japan).

\section{Results}

\section{Clinical characteristics of patients with PA with and with- out DM}

The PA patients with DM (DM+ group) or those without (DMgroup) were compared for clinical characteristics (Table 1). The mean age of the DM+ group was $56.3 \pm 8.3$ years and the $\mathrm{DM}$ - group was $59.9 \pm 9.1$ years $(\mathrm{P}=0.123)$. The $\mathrm{DM}+$ group had 15 men and three woman and the DM-group had 37 men and 15 woman $(P=0.315)$. There were no significant differences in the BMI and hematological parameters between the groups.

The DM+ group had a mean HbA1c of $7.5 \pm 1.3 \%$, a mean duration of diabetes of $5.3 \pm 6.2$ years, and a mean urinary C-peptide of $78.1 \pm 48.4 \mu \mathrm{g} /$ day and the insulin-secretory capacity was shown to be intact in all patients. Of the diabetic complications identified, simple diabetic retinopathy was found in five patients, urinary albumin excretion was found in 10 patients, diabetic neuropathy was found in four patients and no patients exhibited overt nephropathy. The treatments implemented for diabetes were diet therapy in two patients $(11.1 \%)$ and anti-diabetic medications in 16 patients (88.9\%) (insulin + oral hypoglycemic agents (OHAs), three patients (18.8\%); OHAs, 13 patients $(81.2 \%))$.

The presence or absence of DM was examined for its influence on screening, the DM+ group was tended to have high plasma renin activity (PRA) and plasma aldosterone con- 
Table 1. Clinical Characteristics of 70 Patients With PA With and Without DM

\begin{tabular}{|c|c|c|c|}
\hline & PA with DM, mean \pm SD & PA without DM, mean \pm SD & $t$-test, P value \\
\hline $\mathrm{N}$ & 18 & 52 & \\
\hline Age & $56.3 \pm 8.3$ & $59.9 \pm 9.1$ & 0.123 \\
\hline Body mass index $\left(\mathrm{kg} / \mathrm{m}^{2}\right)$ & $26.4 \pm 4.0$ & $24.7 \pm 3.9$ & 0.124 \\
\hline HbAlc (\%) & $7.5 \pm 1.3$ & $5.6 \pm 0.4$ & $<0.001^{*}$ \\
\hline PRA (ng/mL/h) & $0.57 \pm 0.44$ & $0.37 \pm 0.33$ & 0.050 \\
\hline ARR & $891.4 \pm 1231.9$ & $835.5 \pm 906.8$ & 0.838 \\
\hline $\mathrm{ACTH}(\mathrm{pg} / \mathrm{mL})$ & $25.6 \pm 14.8$ & $19.0 \pm 10.6$ & 0.053 \\
\hline Cortisol $(\mu \mathrm{g} / \mathrm{dL})$ & $13.4 \pm 5.8$ & $12.6 \pm 4.1$ & 0.499 \\
\hline Triglyceride (mg/dL) & $153.2 \pm 69.7$ & $129.1 \pm 68.7$ & 0.205 \\
\hline HDL-cholesterol (mg/dL) & $59.3 \pm 28.4$ & $55.4 \pm 14.3$ & 0.452 \\
\hline LDL-cholesterol (mg/dL) & $114.4 \pm 33.9$ & $117.8 \pm 31.5$ & 0.698 \\
\hline
\end{tabular}

${ }^{*} \mathrm{P}<$ 0.05. PAC: plasma aldosterone concentration; PRA: plasma renin activity; ARR: aldosterone-to-renin ratio.

centration (PAC) than the DM- group, but no significant difference in PRA, PAC and aldosterone-to-renin ratio (ARR), respectively.

\section{BP and antihypertensive drugs of patients with PA with and without DM}

The DM+ and DM- groups were compared for BP control and antihypertensive drug use (Table 2). The patients changed their antihypertensive medications after their first presentation to the outpatient clinic to allow for a thorough inpatient workout, and the medications used in the outpatient setting were compared between the DM+ and DM- groups. There was no difference with regard to the duration of hypertension between the groups $(9.7 \pm 7.7$ vs. $8.7 \pm 8.9 ; \mathrm{P}=0.679)$. It took 9 years until PA was diagnosed after starting hypertensive treatment in both groups. While systolic BP and diastolic BP were found to be comparable between the groups, interestingly those in the DM+ group were found to have required significantly more antihypertensive agents than those in the DM- group (number of antihypertensive agents used, $2.0 \pm$ 1.5 vs. $1.3 \pm 1.1 ; \mathrm{P}=0.026$; proportion of patients on three or more agents, $50 \%$ vs. $13 \% ; \mathrm{P}=0.001$, respectively). As a treatment of PA, a total of 21 patients $(30.0 \%)$ underwent surgery. We evaluated the antihypertensive agents in the first outpatient department after PA treatment. We were able to reduce the antihypertensive agents in the operation case of the DM- group $(1.9 \pm 1.1 \rightarrow 0.5 \pm 1.0 ; \mathrm{P}<0.001)$, but the hypertensive agents could not be decreased, even for surgically treated patients, in the $\mathrm{DM}+$ group $(2.8 \pm 1.3 \rightarrow 2.5 \pm$
$2.1 ; \mathrm{P}=0.844)$

\section{CBP of 28 patients with PA with and without DM}

We examined the CBP of 28 PA patients, including eight PA with DM and 20 PA without DM (Fig. 1, Table 3). CBP was tended to be higher in the DM+ group $(151.0 \pm 28.3$ vs. 137.5 $\pm 13.7 ; \mathrm{P}=0.200)$. On the other hand, PAC was higher in $\mathrm{DM}+$ group than in DM- group $(240.3 \pm 118.5$ vs. $138.6 \pm$ 48.6; $\mathrm{P}=0.003)$. Furthermore, a correlation was shown between PAC and CBP ( $\mathrm{r}=0.583 ; \mathrm{P}<0.001)$ (Fig. 2). Multiple regression analyses in $\mathrm{CBP}$ were performed in a core model consisting of the following variables: age, sex and body mass index. PAC was independently associated with CBP (adjust $\mathrm{R}^{2}=0.239$; standardized coefficient $\beta=0.566, \mathrm{P}<0.006$ ) (Table 4).

\section{Discussion}

This study demonstrated that PA complicated by DM required more antihypertensive drugs than PA alone to achieve comparable BP control. Furthermore, in the 28 patients for whom CBP was measured, a positive correlation was shown between $\mathrm{PAC}$ and $\mathrm{CBP}$.

It is becoming clear that patients with PA are more likely to be associated with more serious CV complications than patients with essential hypertension, when matched for severity and duration of hypertension [25]. In the RALES trial [26], as well as in the EPHESUS trial [27], the use of an MR an- 
Table 2. Blood Pressure and Antihypertensive Drugs of Patients With PA With and Without DM

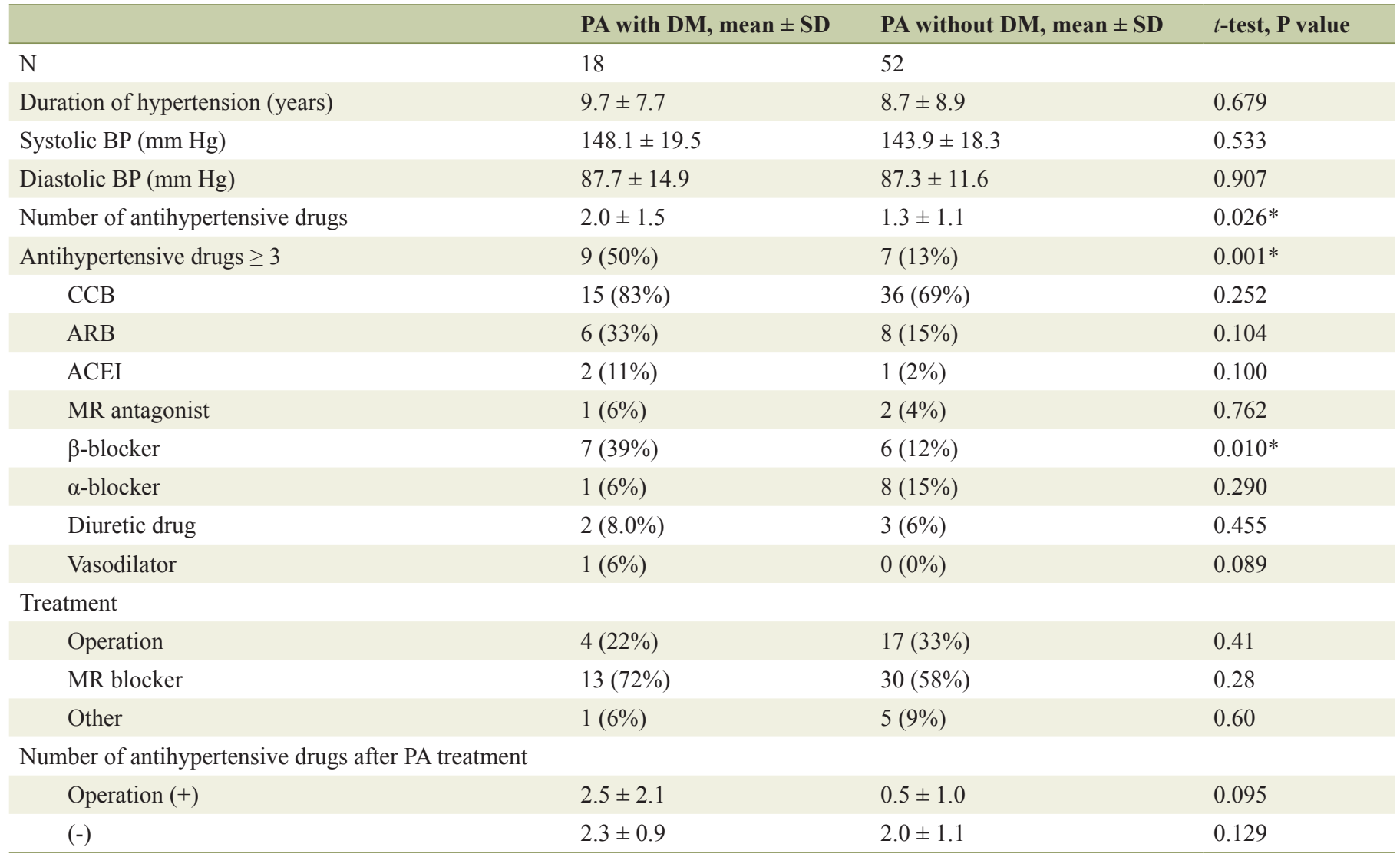

${ }^{*} \mathrm{P}<$ 0.05. CCB: calcium channel blocker; ARB: angiotensin II receptor blocker; ACEl: angiotensin-converting enzyme inhibitor; MR: mineralocorticoid receptor.

tagonist as an add-on to cardiac failure management has been shown to improve prognosis and to be effective in preventing $\mathrm{CV}$ events. These report established aldosterone as an independent risk factor for the $\mathrm{CV}$ system and hyperaldosteronism is associated with advanced arteriosclerotic lesions and cardiac fibrosis [28, 29].

On the other hand, upregulation of the RAAS has been associated to the physiopathology of hypertension in DM pa-

Table 3. Clinical Characteristics of 28 Patients for Whom Measured Central Blood Pressure

\begin{tabular}{llll} 
& PA with DM, mean \pm SD & PA without DM, mean \pm SD & $t$-test, P value \\
\hline $\mathrm{N}$ & 8 & 20 & $0.009^{*}$ \\
Age & $65.0 \pm 13.0$ & $51.6 \pm 10.8$ & 0.485 \\
Sex (male/female) & $7 / 1$ & $5 / 15$ & 0.496 \\
Body mass index $\left(\mathrm{kg} / \mathrm{m}^{2}\right)$ & $25.9 \pm 5.0$ & $24.9 \pm 2.5$ & $<0.001^{*}$ \\
HbAlc $(\%)$ & $7.3 \pm 1.3$ & $5.44 \pm 0.4$ & $0.003^{*}$ \\
PAC (pg/mL) & $240.3 \pm 118.5$ & $138.6 \pm 48.6$ & 0.611 \\
PRA (ng/mL/h) & $0.6 \pm 0.4$ & $0.5 \pm 0.3$ & 0.356 \\
ARR & $530.2 \pm 282.1$ & $414.8 \pm 297.3$ & 0.343 \\
Duration of hypertension (years) & $11.7 \pm 9.1$ & $7.7 \pm 9.1$ & 0.200 \\
Central BP (mm Hg) & $151.0 \pm 28.3$ & $137.5 \pm 13.7$ & 0.642 \\
Systolic BP (mm Hg) & $148.0 \pm 18.7$ & $143.9 \pm 21.6$ & 0.853 \\
Diastolic BP $(\mathrm{mm} \mathrm{Hg})$ & $86.5 \pm 13.4$ & $87.7 \pm 15.9$ & \\
\hline
\end{tabular}

${ }^{*} \mathrm{P}<$ 0.05. PAC: plasma aldosterone concentration; PRA: plasma renin activity; ARR: aldosterone-to-renin ratio. 

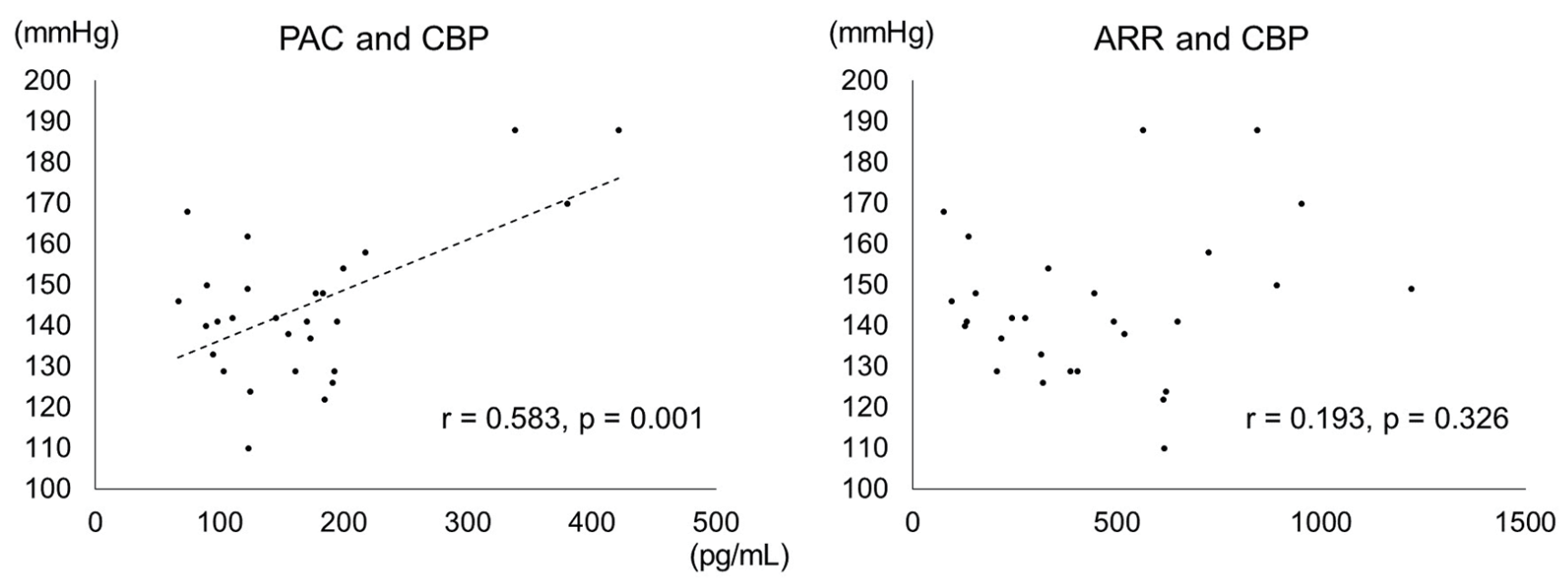

Figure 2. Correlation between PAC, ARR and CBP (based on CBP measurements). In the 28 PA patients for whom measured CBP values were available, a correlation was seen between PAC and CBP $(r=0.58 ; P<0.01)$.

tients $[6,30]$, and the Framingham study showed that patients with DM are at an approximately three-fold risk of developing CV events [31].

In this study, we examined the CBP of 28 PA patients. CBP represents $\mathrm{BP}$ at the aortic root and has been shown to be more strongly correlated with organ damage than peripheral BP [32, 33]. Tomaschitz et al have previously reported that CBP can be predicted from PAC excess and ARR level in patients undergoing coronary angiography [34]. As our result, a positive correlation was shown between PAC and CBP, and PAC was significantly higher in the PA with DM group. However, there was no correlation between ARR and CBP. For this reason, ARR is affected by several factors such as age, sex, plasma potassium concentration, body mass index, etc. [35] and PRA decreases in DM with hypertension patients with advanced diabetic complications [36].

The limitations of this study are: 1) small retrospective analysis of PA patients; 2) we examined the class of the antihypertensive agent but did not examine each dose amount and kind; and 3) though the duration of diabetes was short, $5.3 \pm$ 6.2 years, we could not exclude the influence that diabetes may have had on the arteriosclerosis. Despite these limitations, the current report may be of particular interest in providing findings on PA complicated DM.

In summary, these results suggest that hypertension becomes more difficult to control in PA patients with DM.

Table 4. Multiple Regression Analysis of PAC With CBP

\begin{tabular}{llll}
\hline & Standardized coefficient $(\boldsymbol{\beta})$ & P value & Adjust $\mathbf{R}^{\mathbf{2}}$ \\
\hline & & & 0.239 \\
PAC & 0.566 & $0.006^{*}$ & \\
Age & -0.021 & 0.916 & \\
Sex & -0.096 & 0.619 & \\
BMI & 0.035 & 0.851 & \\
\hline
\end{tabular}

${ }^{*} \mathrm{P}<0.05$.

\section{Conclusions}

PA complicated by DM requires more antihypertensive agents than PA alone to achieve comparable BP control and may be associated with more advanced arteriosclerosis.

\section{Grant Support}

None.

\section{Conflict of Interest}

MS has participated in speaker's bureaus/advisory panels for Sanofi, Daiichi-Sankyo, Astellas, and Tanabe-Mitsubishi. KU has received research support from Terumo, Kowa, Taisho, Arkray, Kyowa Kirin, MSD, Astellas, Boehringer Ingelheim, Ono, Novo Nordisk, Kissei and Tanabe-Mitsubishi and has participated in speaker's bureau/advisory panels for Astellas, Astra Zeneca, Kowa, MSD, Eli Lilly, Taisho, Novo Nordisk and Sanofi. The other authors have no conflict of interest to declare.

\section{Author Contributions}

KO designed and drafted the manuscript and interpreted the data. TH is equal contributor. All authors have made substantial contributions to the conception and design of the study. $\mathrm{TH}$, HS, KY, KT, MS and KU revised the manuscript. KO, TH, YW, KH, RU and HA collected the data. All authors read and approved the final manuscript.

\section{References}

1. International Diabetes Federation. IDF Diabetes Atlas 7th 
Edition. 2015.

2. Iimura O. Insulin resistance and hypertension in Japanese. Hypertens Res. 1996;19(Suppl 1):S1-8.

3. Sakurai M, Saitoh S, Miura K, Nakagawa H, Ohnishi $\mathrm{H}$, Akasaka H, Kadota A, et al. HbAlc and the risks for all-cause and cardiovascular mortality in the general Japanese population: NIPPON DATA90. Diabetes Care. 2013;36(11):3759-3765.

4. Preis SR, Pencina MJ, Hwang SJ, D'Agostino RB, Sr., Savage PJ, Levy D, Fox CS. Trends in cardiovascular disease risk factors in individuals with and without diabetes mellitus in the Framingham Heart Study. Circulation. 2009;120(3):212-220.

5. Kannel WB, McGee DL. Diabetes and cardiovascular disease. The Framingham study. JAMA. 1979;241:20352038.

6. Shimamoto K, Hirata A, Fukuoka M, Higashiura K, Miyazaki Y, Shiiki M, Masuda A, et al. Insulin sensitivity and the effects of insulin on renal sodium handling and pressor systems in essential hypertensive patients. Hypertension. 1994;23(1 Suppl):I29-33.

7. Kereiakes DJ, Chrysant SG, Izzo JL, Jr., Littlejohn T, 3rd, Melino M, Lee J, Fernandez V, et al. Olmesartan/amlodipine/hydrochlorothiazide in participants with hypertension and diabetes, chronic kidney disease, or chronic cardiovascular disease: a subanalysis of the multicenter, randomized, double-blind, parallel-group TRINITY study. Cardiovasc Diabetol. 2012;11:134.

8. Hansson L, Zanchetti A, Carruthers SG, Dahlof B, Elmfeldt D, Julius S, Menard J, et al. Effects of intensive blood-pressure lowering and low-dose aspirin in patients with hypertension: principal results of the Hypertension Optimal Treatment (HOT) randomised trial. HOT Study Group. Lancet. 1998;351(9118):1755-1762.

9. UK Prospective Diabetes Study Group. Tight blood pressure control and risk of macrovascular and microvascular complications in type 2 diabetes: UKPDS 38. BMJ. 1998;317(7160):703-713.

10. Curb JD, Pressel SL, Cutler JA, Savage PJ, Applegate WB, Black H, Camel G, et al. Effect of diuretic-based antihypertensive treatment on cardiovascular disease risk in older diabetic patients with isolated systolic hypertension. Systolic Hypertension in the Elderly Program Cooperative Research Group. JAMA. 1996;276(23):18861892.

11. Tuomilehto J, Rastenyte D, Birkenhager WH, Thijs L, Antikainen R, Bulpitt CJ, Fletcher AE, et al. Effects of calcium-channel blockade in older patients with diabetes and systolic hypertension. Systolic Hypertension in Europe Trial Investigators. N Engl J Med. 1999;340(9):677-684.

12. Cushman WC, Evans GW, Byington RP, Goff DC, Jr., Grimm RH, Jr., Cutler JA, Simons-Morton DG, et al. Effects of intensive blood-pressure control in type 2 diabetes mellitus. N Engl J Med. 2010;362(17):1575-1585.

13. Nishikawa T, Omura M, Satoh F, Shibata H, Takahashi K, Tamura N, Tanabe A. Guidelines for the diagnosis and treatment of primary aldosteronism - the Japan Endocrine Society 2009. Endocr J. 2011;58(9):711-721.

14. Funder JW, Carey RM, Fardella C, Gomez-Sanchez CE,
Mantero F, Stowasser M, Young WF, Jr., et al. Case detection, diagnosis, and treatment of patients with primary aldosteronism: an endocrine society clinical practice guideline. J Clin Endocrinol Metab. 2008;93(9):3266-3281.

15. Gordon RD, Stowasser M, Tunny TJ, Klemm SA, Rutherford JC. High incidence of primary aldosteronism in 199 patients referred with hypertension. Clin Exp Pharmacol Physiol. 1994;21(4):315-318.

16. Rossi E, Regolisti G, Negro A, Sani C, Davoli S, Perazzoli F. High prevalence of primary aldosteronism using postcaptopril plasma aldosterone to renin ratio as a screening test among Italian hypertensives. Am J Hypertens. 2002;15(10 Pt 1):896-902.

17. Omura M, Saito J, Yamaguchi K, Kakuta Y, Nishikawa T. Prospective study on the prevalence of secondary hypertension among hypertensive patients visiting a general outpatient clinic in Japan. Hypertens Res. 2004;27(3):193202.

18. Rossi GP, Bernini G, Caliumi C, Desideri G, Fabris B, Ferri C, Ganzaroli C, et al. A prospective study of the prevalence of primary aldosteronism in 1,125 hypertensive patients. J Am Coll Cardiol. 2006;48(11):2293-2300.

19. Milliez P, Girerd X, Plouin PF, Blacher J, Safar ME, Mourad JJ. Evidence for an increased rate of cardiovascular events in patients with primary aldosteronism. J Am Coll Cardiol. 2005;45(8):1243-1248.

20. Rossi GP, Bernini G, Desideri G, Fabris B, Ferri C, Giacchetti $G$, Letizia $C$, et al. Renal damage in primary aldosteronism: results of the PAPY Study. Hypertension. 2006;48(2):232-238.

21. Takeda R, Matsubara T, Miyamori I, Hatakeyama H, Morise T. Vascular complications in patients with aldosterone producing adenoma in Japan: comparative study with essential hypertension. The Research Committee of Disorders of Adrenal Hormones in Japan. J Endocrinol Invest. 1995;18(5):370-373.

22. Murase K, Nagaishi R, Takenoshita H, Nomiyama T, Akehi Y, Yanase T. Prevalence and clinical characteristics of primary aldosteronism in Japanese patients with type 2 diabetes mellitus and hypertension. Endocr J. 2013;60(8):967-976.

23. Hanslik G, Wallaschofski H, Dietz A, Riester A, Reincke M, Allolio B, Lang K, et al. Increased prevalence of diabetes mellitus and the metabolic syndrome in patients with primary aldosteronism of the German Conn's Registry. Eur J Endocrinol. 2015;173(5):665-675.

24. Seino Y, Nanjo K, Tajima N, Kadowaki T, Kashiwagi A, Araki E, Ito C, et al. Report of the committee on the classification and diagnostic criteria of diabetes mellitus. J Diabetes Investig. 2010;1(5):212-228.

25. Yoshimoto T, Hirata Y. Aldosterone as a cardiovascular risk hormone. Endocr J. 2007;54(3):359-370.

26. Pitt B, Zannad F, Remme WJ, Cody R, Castaigne A, Perez A, Palensky J, et al. The effect of spironolactone on morbidity and mortality in patients with severe heart failure. Randomized Aldactone Evaluation Study Investigators. N Engl J Med. 1999;341(10):709-717.

27. Pitt B, Remme W, Zannad F, Neaton J, Martinez F, Roniker B, Bittman R, et al. Eplerenone, a selective al- 
dosterone blocker, in patients with left ventricular dysfunction after myocardial infarction. $N$ Engl J Med. 2003;348(14):1309-1321.

28. Hillaert MA, Lentjes EG, Kemperman H, van der GraafY, Nathoe HM, Beygui F, Montalescot G, et al. Aldosterone, atherosclerosis and vascular events in patients with stable coronary artery disease. Int J Cardiol. 2013;167(5):19291935.

29. Weber KT, Brilla CG. Pathological hypertrophy and cardiac interstitium. Fibrosis and renin-angiotensin-aldosterone system. Circulation. 1991;83(6):1849-1865.

30. Hayashi T, Shibata H, Kurihara I, Yokota K, Mitsuishi Y, Ohashi K, Murai-Takeda A, et al. High glucose stimulates mineralocorticoid receptor transcriptional activity through the protein Kinase $\mathrm{C}$ beta signaling. Int Heart $\mathrm{J}$. 2017;58(5):794-802.

31. Kengne AP, Turnbull F, MacMahon S. The Framingham Study, diabetes mellitus and cardiovascular disease: turning back the clock. Prog Cardiovasc Dis. 2010;53(1):4551 .
32. Roman MJ, Devereux RB, Kizer JR, Lee ET, Galloway JM, Ali T, Umans JG, et al. Central pressure more strongly relates to vascular disease and outcome than does brachial pressure: the Strong Heart Study. Hypertension. 2007;50(1):197-203.

33. Hashimoto J, Ito S. Central pulse pressure and aortic stiffness determine renal hemodynamics: pathophysiological implication for microalbuminuria in hypertension. Hypertension. 2011;58(5):839-846.

34. Tomaschitz A, Maerz W, Pilz S, Ritz E, Scharnagl H, Renner $\mathrm{W}$, Boehm $\mathrm{BO}$, et al. Aldosterone/renin ratio determines peripheral and central blood pressure values over a broad range. J Am Coll Cardiol. 2010;55(19):2171-2180.

35. Alvarez-Madrazo S, Padmanabhan S, Mayosi BM, Watkins H, Avery P, Wallace AM, Fraser R, et al. Familial and phenotypic associations of the aldosterone Renin ratio. J Clin Endocrinol Metab. 2009;94(11):4324-4333.

36. Christlieb AR. Diabetes and hypertensive vascular disease. Mechanisms and treatment. Am J Cardiol. 1973;32(4):592606. 